Principles and Practice in Organic Chemistry By Prof. J. Lucas and David Pressman. Pp. xi+ 557. (Now York: John Wiley and Sons, Inc.; London: Chapman and Hall, Ltd., 1949.) 48s. net. 7 THERE is always some danger that the student who studies the fundamental principles of chemistry under the heading of physical chemistry may overlook the application of these principles to the operations of the organic chemical laboratory. This volume, which is intended as a class-book for a one-year course of practical organic chemistry, has been designed to guard against such a tendency by directing attention to the physico-chemical aspects of the reactions used in preparative work. In addition, therefore, to the usual preliminary description of general laboratory methods, a first chapter is devoted to such topics as the factors influencing reaction velocity, chemical equilibrium, heats of reaction and of formation, changes in free energy and their calculation from available data. Tables of bond energies, resonance energies and free energies are provided.

In subsequent chapters, which include detailed instructions for preparing more than eighty representative organic compounds, thermochemical and kinetic considerations are discussed at appropriate points. Quantities are stated in moles in order to emphasize molecular proportions and also to facilitate the use of alternative substances in the preparations. Notes and questions, calculated to stimulate thought, are added after each experiment.

The selection of experiments is good. The preparations include a wide range of aliphatic and aromatic substances, a few amino-acids, sugars and heterocyclic compounds, and one chromatographic separation. Typical qualitative reactions of each class of substance are given, and a final chapter provides a brief general scheme of qualitative analysis. This is an excellent book which should help to make the organic laboratory a place of sound general chemical education.

G. M. B.

A Review of Recent Advances in X-Ray Analysis, by Sir W. Lawrence Bragg ; and The Impact of Radioactivity on Inorganic Chemistry, by Prof. H. J. Emeléus

(Post-Graduate Lectures given to the Oil and Colour Chemists' Association.) Pp. 99+10 plates. (Cam. bridge : W. Heffer and Sons, Ltd., 1950.) 12s. 6 d. net.

T HIS short volume contains the substance of two groups of three lectures, each on the subjects indicated in the title and delivered before the Oil and Colour Chemists' Association in 1947 and 1948. The choice of subjects for these lectures is particularly appropriate since both $\mathrm{X}$-ray analysis and radioactivity have a widespread and growing interest in many branches of science. Moreover, the authors are not only acknowledged experts in their respective fields, but also have the happy knack of presenting scientific information in a lucid and interesting way.

In the first three lectures, Sir Lawrence Bragg describes X-ray analysis by analogy with the optical diffraction grating, with illustrations derived from the structures of many inorganic compounds; he then discusses the variations from the perfect lattice, the structure of some elements and metal alloys, and concludes with a description of work on X-ray analysis of organic compounds. The diffieulty and labour of interpreting the results in X-ray work is very well brought out in these lectures. Prof. H. J.
Emeléus develops his theme of radioactivity against a historical background and follows this account, which includes atomic fission and the chemistry of the transuranic elements, with a discussion of the measurements, handling and production of radioactive substances. The final lecture describes some of the manifold applications of radioactive tracers in chemistry and biology.

The scope of the subject-matter is necessarily limited in a book of this size, but there is much stimulating information which should appeal to a very wide circle of resders wishing to know more about developments in these two very important subjects. It is pleasant to see a book which is not only very moderate in price according to present-day standards, but is also well bound, printed and illustrated.

F. H. Burstati

\section{Trilinear Chart of Nuclear Species}

By William H. Sullivan. Pp. 4+chart (in 6 strips) $10 \frac{1}{2}$ in. $\times 194$ in. (New York: John Wiley and Sons, Inc.; London: Chapman and Hall, Ltd., 1949.) 20s. net.

THE trilinear chart has been developed from the more familiar charts of nuclear properties in which $(A-Z)$ or $A$ is plotted against $Z$ (where $A$ and $Z$ are the atomic mass and atomic number respectively). It allows the simultaneous plot of $A$ against $Z,(A-Z)$ against $Z$ and $(A-Z)$ against $A$, so that isotopes, isobrrs, isotones (nuclides with the same number of neutrons) and isodiapheres (nuclides with the same excess of neutrons) lie on straight lines. All known nuclides are represented by hexagonal panels, those which occur naturally being distinguished from those produced artificially by different background colours. Nuclear physical constants (natural isotope abundance, angular momentum, slow neutron cross-section, half-life, etc.) are shown in the panel of each nuclide. However, such an extensive list of symbols (fourteen in all) requires some reference to the key, and it would perhaps have been advisable to tabulate some of the data (for example, fission yields). The printing on the green field (naturally occurring nuclides) is clear, but a bolder type could have been used to advantage on the lavender background (artificially produced nuclides).

\section{Modern Synthetic Rubbers}

G. B. CooK

By Dr. Harry Barron. Third edition, revised and enlarged. Pp. xix +636 . (London: Chapman and Hall, Ltd., 1949.) 45s. net.

THE third edition of "Modem Synthetic Rubbers" is excellently produced and well illustrated, and contains much new information which has been obtained from B.I.O.S. and C.I.O.S. reports. There is also a new section on compounding.

The author sets out to cover in the very short space of six hundred pages the field of synthetic rubber production and technology from preparation of the monomers to processing of the elastomers. The result is that emphasis is almost entirely on the practical aspects of synthetic rubber production, and at times this leads to a catalogue-like style of presentation. However, the merits of the book more than compensate for the mental indigestion occasionally induced. Mistakes are few, but the reviewer was surprised to find the statement that rubber has a "trans" structure and gutta-percha a "cis" configuration appearing in the third edition of this work.

The book should prove of interest to all who are interested in the study of high polymers. 